\title{
Biodegradation of Diesel by Aeromonashydrophila
}

\author{
Lakshmi Priya .J \\ Microbiology department,K.S.Rangasamy College of Arts and Science, Tiruchengodel Periyar University/India
}

\begin{abstract}
Hydrocarbon degrading microorganisms play a major role in the environment.. The purpose of the present study was to enumerate of Aeromanas sp from oil contaminated soil and to study degrading capacity, emulcification activity and production of biosurfactant. The hydrocarbon substrate specificity test shown that diesel is also one of the best substrate for growth and emulsification of biosurfactant by Aeromonas. Among 6 strains of Aeromonas, frist strain(A1) shows maximum degradation rate at end of $168 \mathrm{hrs}$ upto19.37\% followed by other strains, about $75 \%$ of diesel was degraded by Aromonas over a period of 7days. Emulsification upto $75 \%$ by A1 followed by A2(63.75\%),A3(57.5\%), Biosurfactant production by A1 strain 0.064g/1 followed by other strains it represents a new type of biosurfactant with strong emulsifying ability.
\end{abstract}

Keywords: Aeromonas, Biosurfactant, Diesel, Emulsify, Soil

\section{Introduction}

Biodegradation is the partial or complete conversion of the compound of interest to its elements. The role of organisms, both micro-and macro-organisms, in biodegradation is complex. It is a function of the organism's presence in an environment, their ecology, their metabolism (enzyme complement and efficiencies), growth rate and kinetics (of both growth and metabolism). It has been known for several decades that microorganisms possess both aerobic and anaerobic degradation. Microorganisms are actively involved in the degradation of several naturally occuring and toxic substances such as petroleum hydrocarbons, pesticides etc., Aerobic biodegradation is the breakdown of organic contaminants by microorganisms when oxygen is present. Aerobic bacteria use oxygen as an electron acceptor, and break down organic chemicals into smaller or organic compounds, often producing carbon dioxide and water as the final product. Aerobic biodegradation is also known as aerobic respiration. Aerobic biodegradation is an important component of the natural attenuation of contaminants at many hazardous waste sites. Anaerobic biodegradation is the breakdown of organic contaminants by microorganisms when oxygen is not present. Some anaerobic bacteria use nitrate, sulfate, iron, manganese, and carbon dioxide as their electron acceptors. And break down organic chemicals into smaller compounds, often producing carbon dioxide and methane as the final products. Anaerobic biodegradation is an important components of the natural attenuation of contaminants at many hazardous waste sites.

The most striking feature of a survey of the microorganisms involved in biodegradation processes is their large numbers, ubiquitous presence and varied capabilities. Rather that list the organisms involved (including the bacteria, fungi, actionmycetes, protozoa, etc.) a very brief treatment of the reasons for this versatility is given. Microorganisms as a group show a very wide tolerance range for environmental factors very low to very high $\mathrm{pH}$ levels, $0^{\circ} \mathrm{C}$ to $80^{\circ} \mathrm{C}$ temperature, of the reasons for this versatility is given.

Biodegradation of organic compounds is the partial simplification or complete destruction of their molecular structure by physiological reactions catalyzed by microorganisms (Alexander, 1981; Atlas and Bartha, 1992; Young, 1997). Biodegradation is routinely measured by applying chemical and physiological assays to laboratory incubations of flasks containing pure cultures of microorganisms, mixed cultures, or environmental samples (e.g. soil, water, sediment, or industrial sludges). Oxygen is one of the most important requirements for microbial degradation of hydrocarbons. However, its availability is rarely a rate-limiting factor in the biodegradation of marine oil spills. Microorganisms employ oxygen-incorporating enzymes to initiate attack on hydrocarbons. Anaerobic degradation of certain hydrocarbons (i.e., degradation in the absence of oxygen) also occurs, but usually at negligible rates. Such degradation follows different chemical paths, and its ecological significance is generally considered minor. Studies of sediments impacted by the Amoco Cadiz spill found that, at best, anaerobic biodegradation is several orders of magnitude slower than aerobic biodegradation (Ward et al., 1980).

\subsection{Hydrocarbons and its impact on the environment}

Petroleum hydrocarbons existed long before humans developed the technological ability to retrieve it from the earth and use it as a source of energy. Natural seeps with in the ocean floor have been releasing the hydrocarbons for thousands of years creating ecosystems with adaptive microorganisms that utilize petroleum effectively. However, the ecological balance in environments that are not adjusted to assimilating large amount of spills or released from large quantity transportation and extraction practices. 
Since the mid-1980's, hydrocarbon contamination has become a critical environmental issue in the world due its adverse environmental and health effects. Hence, increasing attention is being given to the study and development of techniques for cleaning up this contamination. To understand the potential environmental impact that can occur during the oil spill, the molecular components of petroleum hydrocarbons must be considered. The natural composition of petroleum diesel is very complex.

Petroleum hydrocarbon continues to be used as the principle source of energy and hence an important global environmental pollutant. Apart from accidental contamination of ecosystem, the vast amounts of oil sludge generated in refineries from water oil separation system and accumulation of waste oily materials in crude oil storage tank bottoms pose great problems because of the expensive disposal methods. (Ferrari et al., 1996; Vasudevan and Rajaram, 2001). Despite decades of research, successful bioremediation of petroleum hydrocarbon contaminated soil remains challenge.

Concentration of inorganic nutrients often limits the biodegradation of petroleum hydrocarbons in marine environment. Atlas and Bartha (1972) found that microbial degradation and mineralization were not increased by nitrate or phosphate alone but were increased dramatically when nitrate and phosphate were added together.

\subsection{Distribution of hydrocarbon degrading microorganisms}

It has been known for several years that certain microorganisms are able to degrade petroleum hydrocarbons and use them as sole source of carbon and energy for growth. The ability to degrade and/or utilize hydrocarbons substrates is exhibited by wide variety of bacterial genera, 25 genera of hydrocarbon degrading bacteria (Floodgate, 1984) have been isolated from the marine environment. Similarly 22 genera of hydrocarbon degrading bacteria have been reported (Bossert and Bartha, 1984) based on the number of published.

Microbial remediation of toxic hydrocarbon contaminated sites is carried out by a diverse group of microorganisms. Study of this diversity at the genetic level is necessary to understand the phylogenetic perspective, the mechanism of degradation, and develop novel strategies of treatment. Analysis of microorganisms having high specificity for recalcitrant compound. Documentation of this microbial diversity from oily sludge/crude oil contaminated sites is essential because they create a major environmental concern and these microbes can be used for cleaning up the same ().

Microbial degradation of oil has been shown to occur by attack on aliphatic or light aromatic fractions of the oil, with high molecular weight aromatics, resins, and asphaltenes considered to be recalcitrant or exhibiting only very low rates of biodegradation (Joseph et al., 1990) Broderick and Coony (1982) reported that $96 \%$ of hydrocarbon utilizing bacteria isolated from freshwater lakes were able to emulsify kerosene, and it has been observed that mixed cultures of marine and soil bacteria which effectively degrade crude oil also exhibit strong emulsifying activity. Both aerobic and anaerobic biodegradation have been shown to reduce the concentration of several components of petroleum hydrocarbons. Mixed cultures often involve significant degradative capabilities because the single strains can complement to one another due to their physiological properties. Therefore, some members of the culture might be able to provide important degradative enzymes whereas other supply surfactants or growth factors.

\section{Degradation pathway for hydrocarbons}

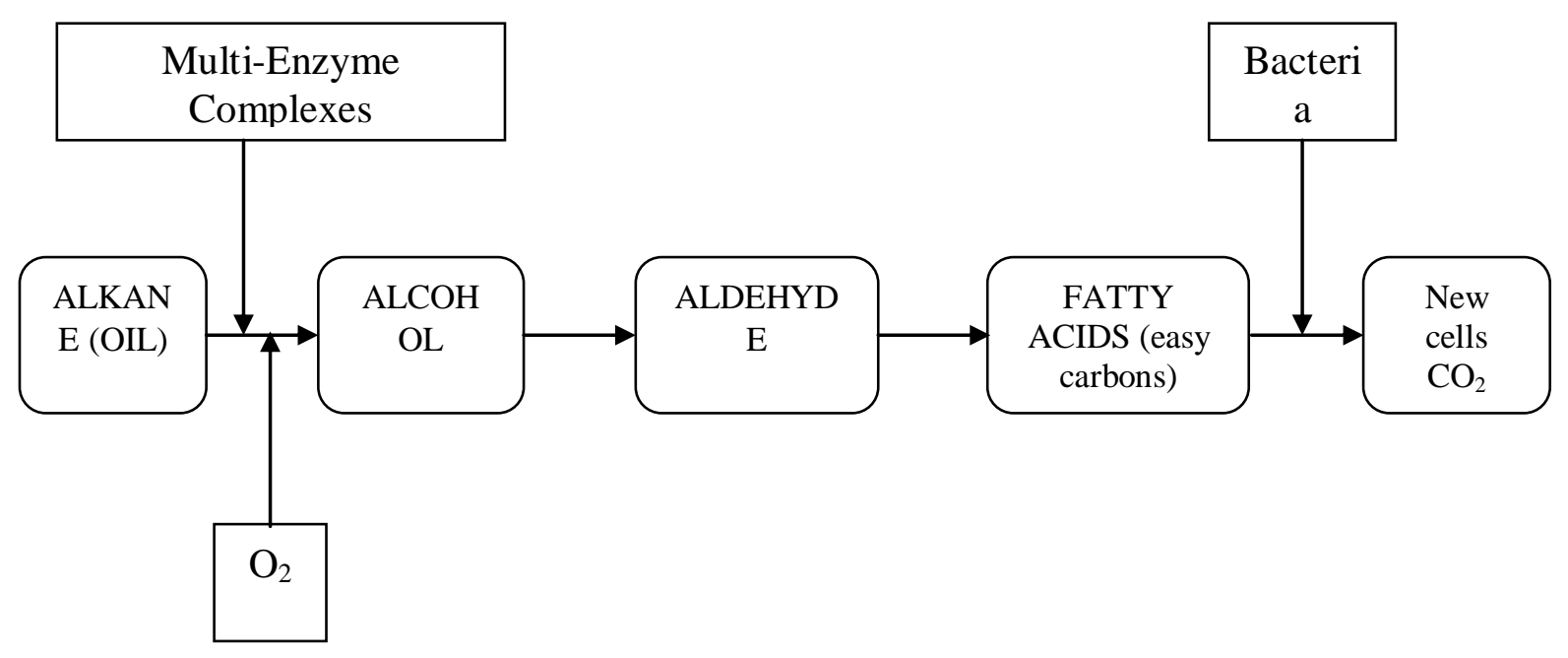


During oil biodegradation, oil fluid properties change because different classes of compounds in petroleum have different susceptibilities to biodegradation. The early stages of oil biodegradation are characterized by loss of $n$ paraffin followed by loss of acyclic isoprenoids. Compared with those compounds groups, other compound classes are more resistant to biodegradation. However, even those more resistant compound classes are eventually destroyed as biodegradation proceeds. Hydrocarbons are natural products as well as pollutants; it is not surprising that hydrocarbon oxidizing bacteria, fungi and algae are distributed widely in nature. A typical soil, beach sand or ocean sediment contains $10^{4}$ to $10^{6}$ hydrocarbon degrading microorganisms per gram of soil (Rosenberg, 1991).

\subsection{Characteristics of diesel}

One can obtain diesel from petroleum, which is sometimes called petrodiesel when there is a need to distinguish it from diesel obtained from other sources. As a hydrocarbon mixture, it is obtained in the fractional distillation of crude oil between $250^{\circ} \mathrm{C}$ and $350^{\circ} \mathrm{C}$ at atmospheric pressure. Diesel is generally simpler to refine than gasoline and often costs less (through price fluctuations often mean that the inverse is true).

Reducing the level of sulfur in diesel is better for the environment. It allows the use of catalytic diesel particulate filters to control diesel particulate emissions, as well as more advanced technologies, such as Nox absorbers (still under development), to reduce emissions of nitrogen oxides (Nox). However, lowering sulfur also reduces the lubricity of the fuel, meaning that additives must be put into the fuel to help lubricate engines. Diesel contains approximately $18 \%$ more energy per unit of volume than gasoline, which along with the greater efficiency of diesel engines contributes of fuel economy (distance traveled per volume of fuel consumed). In the maritime field various grades of diesel fuel are used.

\subsection{Role of Aeromonas in the degradation of hydrocarbons}

Aeromonas is a non motile, gram negative rod shaped bacteria, chemoorganotrophic facultative anaerobes demonstrating both respiration and fermentative metabolism. Although it is a pathogen to human as well as fish, $29.6 \%$ of total population of Aeromonas were reported in soil followed by Pseudomonas and Bacillus.

Like Pseudomonas and Bacillus sp. Aeromonas also play a vital role in hydrocarbon degradation and production of biosurfactant. The peak growth and biosurfactant production was an the $8^{\text {th }}$ day (Ilori et al., 2005). Hydrocarbon degrading microorganisms plays a major role in the environment. Crude oil degrading bacterial strains were isolated from refinery oil contaminated soil which includes the Aeromonas sp. the rate of degradation at the $8^{\text {th }}$ day $53.55 \%$ (Vivekanandhan et al., 1999)

Several studies on production of biosurfactants by Aeromonas sp. were also reported (Desai et al., 1987; Lang et al., 1987; Rosenberg, 1986; Wilkinson et al., 1985).

\subsection{Biosurfactants}

\subsubsection{Classification of biosurfactants}

Biosurfactants can be classified in several broad groups: Glycolipids, lipopeptides, lipopolysaccharides, phospholipids, fattyacids, and neutral lipids. The classification of biosurfactants is based on their chemical nature. Low molecular weight substances (e.g., rhamnolipid phospholipids, peptides), polymeric materials (e.g., proteins, polysaccharides) or particulate compounds (e.g., extracellular vesicles or microbial cells) (Rosenberg, 1986)

\subsubsection{Production of biosurfactants by microorganisms}

Biosurfactants, which are natural emulsifiers of hydrocarbons, are produced by some bacteria, fungi and yeast. Biosurfactant is defined as a surface active molecule containing both hydrophobic and hydrophilic components which is produced by microorganisms.

Biosurfactants can improve the bioavailability of hydrocarbons to the microbial cells by increasing the area at the aqueous hydrocarbon interface. This increases the rate of hydrocarbon dissolution and thereby utilization by microorganism (Gerson, 1993). Surface active biosurfactants are employed for enhanced oil recovery (Hart, 1989) and as flocculating agents, as detergents and adhesives (Zajie and Saffens, 1984).

\subsubsection{Application of bio-surfactants}

Research in the area of biosurfactants has expanded quite a lot in recent years due to its potential use in different areas, such as the food industry; agricultural, pharmaceutical, oil industry, neurochemistry and the paper and pulp industry. The development of this line of research is of paramount importance, mainly in view of the present concern with protection of the environment. Therefore, the most significant advantage of microbial surfactants over chemical surfactants is its ecological acceptance because of its biodegradability and nontoxic to natural environments. The emphasis to date has been on enhanced oil recovery, cleaning oil spills, oil 
emulsification and in breaking industrially derived oil-in-water and water-in-oil emulsions. Dispersion and solubilization of organic compounds having low water solubility is an important step in bioremediation. Biosurfactants offer potential for dealing with this problem by increasing the dispersion and solubilization of organic compounds having limited water solubility.

Biosurfactants have been used for gene transfection, as ligands for binding immunoglobulins, as adjuvants or antigens and also as inhibitor for fibrin clot formation and activators of fibrin clot lysis. Biosurfactants have the potential to be used as a preventive strategy to delay the on set of pathogenic biofilm growth on catheters and other medical insertional materials, thus lowering the large number of hospital infections without the use of synthetic drugs and chemicals. In spite of the immense potential of the biosurfactants, their use still remains limited, because of their comparatively high production cost, as well as scant information on their toxicity towards human systems. However, it is only a matter of time before the full potential of biosurfactants is fully exploited and used in medical science (Karnath et al., 1999).

\section{Importance Of The Present Investigation}

Petroleum hydrocarbon continues to be used as the principle source of energy. Wide scale production, transport use and disposal and petroleum globally have made it a major containment in both prevalence and quantity in the environment. Biosurfactant are a group of surface-active molecules produced mainly by hydrocarbon degrading microorganism it can degrade or transform the components of petroleum products. They are non-toxic, non-hazardous, Biodegradable and environmentally friendly components. Hence, reclamation of petroleum hydrocarbon polluted sites can be carried out by bioremediation, which is can enhance natural process of biodegradation using biosurfactant producing and oil degrading bacterial cultures. Bioremediation technologies generally aim at providing favourable conditions of certain, temperature and nutrients to enhance biological hydrocarbon break down.

Most work on biosurfactant production by microorganisms has been concentrated on the determination of the distinct polar moieties used for categorization into classes such as glycolipids and lipoproteins. While biosurfactant production by organisms such as Pseudomonas sp. Achinetobacter sp. Bacillus sp. Rhodococcus sp. and Arthobacter sp. have been well studied, only a few reports exist on the ability of Aeromonas sp. to the best of our knowledge, to produce biosurfactant when grown on hydrocarbon. Among the soil microorganisms which includes Bacillus and Pseudomonas, the presence of Aeromonas ranges about 29\%. Apart from its pathoginicity in humans and fish, its also play a vital role in hydrocarbon degradations.

In the case of above mentioned discussion the present study is designed to carry out the following objectives.

1. To enumerate of Aeromonas sp. from oil contaminated soil.

2. To study the degradation capacity of Aeromonas sp.

3. To study the emulsification activity.

4. To estimate the biosurfactant production.

\subsection{Collection of soil samples}

\section{Materials And Methods}

The oil contaminated soil samples were collected from petrol station at Tiruchengode in a sterile polythene bag and transported to laboratory within one hour. The samples were processed by enrichment method to enumerate oil degrading Aeromonas sp.

\subsection{Enrichment method}

One hundred millilitres of Mineral Salts Medium (MSM) was distributed in flasks and $1 \mathrm{~g}$ of soil was added into the medium followed by the addition of $0.5 \%$ of diesel as carbon source. The flask was kept in the shaker (110 rpm) at room temperature for uniform distribution of diesel. After $24-48 \mathrm{hrs} 1 \mathrm{ml}$ of the liquid culture was transferred to fresh MSM for second enrichment and $0.5 \%$ diesel was again added as carbon source and the flasks were kept in a shaker at room temperature for $24-48 \mathrm{hrs}$. After incubation, samples were serially diluted and plated over nutrient agar medium and incubated at room temperature for $24-48 \mathrm{hrs}$. Morphologically different colonies were isolated and considered as hydrocarbon utilizing organisms. Among which, Aeromonas colonies were selected and transferred to mineral salt medium (MSM), supplemented with $0.5 \%$ of diesel. After $24-48 \mathrm{hrs}$ of incubation a loopful of liquid culture was streaked on agar plates and sub- 
cultured on fresh agar plates, in order to get the pure culture of Aeromonas. The isolates were maintained on nutrient agar slants at $4^{0} \mathrm{C}$ and sub cultured every 2 weeks.

\subsection{Identification and characterization of Aeromonas sp.}

The morphological and biochemical tests as per Bergey's Manual of Systematic Bacteriology (1994).

\section{Growth substrate range determination (Ilori et al., 2005)}

The ability of the isolate to utilize diesel as sole carbon source pf carbon and energy was determined. The carbon source $\left(0.5 \%, \mathrm{vv}^{-1}\right)$ was added to MSM $(100 \mathrm{ml})$ contained in $250 \mathrm{ml}$ Erlenmeyer flasks. A noninoculated control flask was prepared for comparison purpose. The media, after sterilization, were inoculated with test organism. Incubation was with shaking $(120 \mathrm{rpm})$ at room temperature $\left(30 \pm 2^{0} \mathrm{C}\right)$ for 7 days.

\section{Composition of media}

The mineral salts medium (MSM) (Kastner et al., 1994) containing the following composition was used.

Disodium hydrogen phosphate

Dipotassium hydrogen phosphate -

Ammonium Chloride

Magnesium Sulphate

Distilled water

$\mathrm{pH}$

\section{$2.13 \mathrm{~g}$}

$\begin{array}{ll}1.3 \mathrm{~g} & \\ - & 0.5 \mathrm{~g} \\ - & 0.2 \mathrm{~g} \\ - & 1 \mathrm{~L} \\ - & 7\end{array}$

Composition of trace elements (Bauchop and Elsden, 1969)

$\begin{array}{lll}\text { Boron } & - & 0.025 \% \\ \text { Copper Sulphate } & - & 0.05 \% \\ \text { Manganese Sulphate } & - & 0.05 \% \\ \text { Molybdenum Chloride } & - & 0.006 \% \\ \text { Zinc Sulphate } & - & 0.07 \% \\ \text { Distilled Water } & - & 100 \mathrm{ml} 3\end{array}$

3.5 Estimation of biomass (Rahman et al., 2002)

$3 \mathrm{ml}$ of the samples were withdrawn from the culture flasks two days interval and centrifuged at 4000rpm for 20minutes. The pellet containing cells was dried in an oven at $110^{\circ} \mathrm{C}$ and the biomass was calculated.

\subsection{Emulsification (Iqbal et al., 1995)}

The ability to emulsify liquid hydrocarbons, diesel was determined. The $2 \mathrm{ml}$ broth was add into each test tube (diesel $2 \mathrm{ml}$ ). The content of the tubes were vortexed at high speed for $2 \mathrm{~min}$ and left undisturbed for $24 \mathrm{~h}$. The emulsion index was determined as the height of the emulsion layer divided by the total height and multiplied by 100 .

\subsection{Surface tension measurement (Lang and Wanger, 1987)}

Surface tension is defined as the force acting perpendicular to a line of unit length drawn on an imaginary plane of film of a liquid or in other terms the force capable of, to bind the drop, of liquid together in itself to give the maximum possible size if it could hang by its own weight under gravity. This definition also leads to its measurement by simple technique called drop weight method. By this method, a vertical fine capillary nozzle having round tapered mouth is required. The liquid is passed slowly to make a fine drop which hangs by its own weight and then falls down by gravity. The weight of a single drop from cell free supernatant was measured by taming average of several statistical weight data of 200 drops for each sample.

The following emperical formula was applied to calculate the surface tension in $\mathrm{mN} / \mathrm{m}$.

Where,

$$
\mathrm{T}=\frac{m x g}{3.8 x r}
$$

$\mathrm{m} \quad=$ mass of a single drop of liquid $(\mathrm{kg})$

$\mathrm{r} \quad=$ outer round tapered radius of the nozzle $(\mathrm{m})$

\subsection{Biosurfactant estimation (Zhang et al., 1992)}

Cell-free culture broth $(1 \mathrm{ml})$ was added to $4.5 \mathrm{ml}$ of dilute sulfuric acid $(6: 1 \mathrm{v} / \mathrm{v})$ and mixed thoroughly. The mixture was heated at $100^{\circ} \mathrm{C}$ for $10 \mathrm{~min}$ and cooled to room temperature. To the mixture was added $0.1 \mathrm{ml}$ of 
freshly prepared $3 \%$ solution of thioglycolic acid, and the mixture was incubated in darkness for $3 \mathrm{~h}$. absorbance was measured at 400 and 430nm spectrophotometrically. Rhamnolipid concentration was calculated using the formula

$$
\mathrm{RL}=\left[54.18\left(\mathrm{~A}_{400}-\mathrm{A}_{430}\right)-1.49\right] \mathrm{F}
$$

Where $\mathrm{A}_{400}$ and $\mathrm{A}_{430}$ are absorbances at 400 and 430nm, respectively, and $\mathrm{F}$ is the dilution factor. A standard curve prepared using different concentrations of L-rhamnose (Sigma) was used to determine the rhamnolipid concentration.

\section{Enumeration of bacterial population}

\section{Results And Discussion}

The total heterotrophic bacterial population (THB) from oil contaminated soil samples was enumerated. After the enrichment process, $1 \mathrm{ml}$ of enriched culture was serially diluted and plated using pour plate technique. The THB population was ranged between $1.6 \times 10^{5}$ and $3.4 \times 10^{6} \mathrm{cfu} / \mathrm{g}$ whereas in uncontaminated soil, the THB population may vary between $10^{7} \sim 10^{9} \mathrm{cfu} / \mathrm{g}$. This variation is due to the presence of hydrocarbon in the contaminated soil. As per the studies of Rahman et al (2003) the size of the microbial population decrease is based on the chemical composition of contaminating oil and species of microorganisms present in the microbial community of particular ecosystem. Plate counts confirm the presence of a significant number of hydrocarbon-oxidizing organisms in soil. Morphologically different isolates were observed on the nutrient agar plates.

As it was aimed to work on the degradative potential of Aeromonas species, oxidase and catalase positive isolates were subjected to biochemical analysis. Gram-negative rod, motile, urease negative, it utilized lysine, citrate and produced gas from glucose. Maltose and lactose were not utilized. The organism reduced nitrate, utilized ornithine, but not sorbitol. It was therefore putatively classified as the species of Aeromonas, taken for the present investigation.

In unpolluted ecosystem, hydrocarbon utilizers generally constitute less than $0.1 \%$ of the microbial community and in oil polluted ecosystems they can constitute upto $100 \%$ of the viable microorganisms. The microbial populations quantitatively reflect the degree or extent of exposure of that ecosystem to hydrocarbon contamination (Atlas 1981, Al- Gounaim et al., 1995).

The rapidly expanding literature on the oxidation and assimilation of hydrocarbon substrates by soil microorganisms attests to the widespread occurrence and ease of isolating these organisms from nature (McClay et. al., 2000 and Van Dyke, 1991). Population levels of hydrocarbon utilizers and their population within the microbial community appear to be a sensitive index of environmental exposure to hydrocarbons.

Microorganisms are known to attack specific compounds present in crude oil that is a complex mixture of saturates, aromatics and polar compounds (Bharathi and Vasudevan, 2001). An effective degradation of crude oil would require simultaneous action of several metabolically versatile microorganisms with favorable environmental conditions such as $\mathrm{pH}$, temperature and availability of nutrients (Venkateswaran and Harayama, 1995). An oil spill in the environment leads to an adaptive process and if metabolically active hydrocarbon utilizing microorganisms could respond would be reduced considerably. The necessity for seeding with complementary population may not be capable of degrading a wide range of potential substrates in a complex mixture such as crude oil (Chhatre et al., 1996).

\section{Growth substrate range determination}

The results of the hydrocarbon substrate specificity test revealed that the organism had good growth on diesel as substrate. When no difference was noticed in the turbidity of the test flask and that of the control, it was taken as no growth (-), when slight increase in turbidity was noticed, it was taken as poor growth (+). Significant increase in turbidity was taken as good growth $(++)$.

In the present study among six strains of Aeromonas, four strains shows increase in turbidity in the presence of diesel as substrate was taken as good growth (++) and two strains shows slight turbidity was taken as poor growth (+). Thus the substrate specificity test conclude that diesel also act as best substrates for growth of hydrocarbon degraders (Table 1).

The addition of hydrocarbons to an ecosystem may result in a selective increase in microorganisms capable of utilizing the hydrocarbons and those that are capable of utilizing metabolites produced by the hydrocarbon-utilisers (Venkateswaran and Harayanma, 1995, Ferrari et al., 1996). The enhancement or 
reduction will depend upon the chemical composition of the contaminating hydrocarbons and on the species of microorganisms present within the microbial community of the particular ecosystem (Atlas, 1995).

The added oil enriched for the species that have inherent petroleum hydrocarbon assimilating potential (Bossert and Bartha, 1984), whereas the less adapted species among the total heterotrophic population are gradually eliminated, resulting in qualitative shifts in species composition (Amadi, 1990).

\section{Degradation of diesel}

Hydrocarbon degradation by microbial communities depends on the composition of the community and its adaptive response to the presence of petroleum hydrocarbon. The organism used in this study was isolated from oil contaminated soil samples from petrol station at Tiruchengode, the organism therefore might have had prior exposure to hydrocarbons like diesel, thus it shows good growth in diesel.

In the present study the bacterial strain Aeromonas developed from oil polluted sites grown well on diesel .The rate of degradation is proportional to the bacterial population. The degradation of diesel was observed at every $24 \mathrm{hrs}$ interval and there was a corresponding increase in the bacterial cell population. The degradation of diesel after $24 \mathrm{hrs}$ was $2.57 \%$ at the end of $168 \mathrm{hrs}$ strain A1 degraded upto $19.37 \%$, shows maximum degradation followed by the other strains (Table 2 and Figure 1).

The rate of microbial degradation of hydrocarbons in soils is affected by several physico-chemical and biological parameters including the number and species of microorganisms present, the conditions for microbial degradation activity (e.g. presence of nutrient, oxygen, $\mathrm{pH}$ and temperature) the quality, quantity and bioavailability of the contaminants; and the soil characteristics such as particle size distribution (Margesin and Schinner, 1997).

Isolation of degrading strains was performed with diesel oil, crude oil as sole carbon source, the result showed a reduction of $30 \%$ while this value decreased to $0.15 \%$ in uncontaminated samples, which includes the strains of Aeromonas sp and Pseudomonas vasicularis (Saagua et al., 2002).

Petrodiesel oil degraders belong to the genera Micrococcus, corynebacterium, Bacillus, Entrobacter, Pseudomonas, Alcaligenes, Flavobacterium, Moraxella, Aeromonas, Acinetobacter and Vibrio. The flora reflects the normal hetrotropic bacteria present in soil and native genera seem to be crude oil utilisers. Several other workers also reported on the above genera as hydrocarbon degrading microorganisms (Atlas 1981, Leahy and Colwell 1990, Banat et al ., 2001).

The rate of hydrocarbon degradation ranged from $0 \mu \mathrm{gg}^{-1}$ to $0.60 \mu \mathrm{gg}^{-1}$ for control oil, $0.05 \mu \mathrm{gg}^{-1}$ to 1.67 gasoline and from $0.12 \mu \mathrm{gg}^{-1}$ diesel oil to $1.31 \mu \mathrm{gg}^{-1}$ for hydrocarbon contaminated soils respectively (Obire, 2001). The biodegradability of seven different crude oils was found to be highly dependent on their composition and on incubation temperature. At $20^{\circ} \mathrm{C}$ lighter oils had greater abiotic losses and were more susceptible to biodegradation than heavier oils (Atals, 1995).

Chhatre et al., (1996) reported about $60 \%$ of degradation of crude oil using semicontinuous crude oil fed reactor using a four members consortium. Several other workers (Venkateswaran and Harayama 1995, Lal and Khanna, 1996, Sugiura et al., 1997) showed that a bacterial consortium was able to degrade $28-51 \%$ of saturate and 0$18 \%$ of aromatics present in crude oil or up to $60 \%$ crude oil by mixed consortia. The percentage of biodegradation was significantly higher than that achieved by individual isolates.

By the addition of metabolically active hydrocarbon utilizing microorganisms, the lag period before the indigenous microbial population respond to the addition of a complex mixture such as diesel oil can be reduced considerably (Del'Arco and De Franca, 1999; Bharathi and Vasudevan, 2001). Several other workers (Chhatre et al., 1996; Sugiura et al., 1997; Vasudevan and Rajaram, 2001) have described the ability of mixed bacterial consortia to degrade $28-51 \%$ of saturates and $0-18 \%$ of aromatics present in petrodiesel or upto $60 \%$ petrodiesel. Biostimulation and bioaugmentation on the degradation of total petroleum hydrocarbon (TPH) in soils contaminated by diesel oil, showed the greatest degradation upto $72.7 \%$ by the number of diesel oil degrading microorganisms includes Aeromonas, Bacillus, Acinetobacter (Fatima et al., 2003).

A survey of soils from the northwest area of Canada for the presence of oil-utilizing microorganisms indicated that not all soils have an indigenous population capable of utilizing oil degradation rates of the bacterial consortium such as Flavobacterium and Cytophaga (41\%), Pseudomonas sp. (34\%), Xanthomonas (9\%), Aeromonas (17\%) respectively (Jobson et al., 1972).

\section{Emulsification}

The formation of a water-in-oil mixture. An emulsified mixture of water in oil is commonly called mousse. The presence of mousse indicates that a spill has been on the water for some time.

The liquid aromatic hydrocarbons were particularly not good substrates for emulsification, however diesel was found to be good substrates for emulsification in the present study out of 6 strains of Aeromonos A1, A2, A3 shows $75 \%, 57.5 \%, 63.75 \%$, respectively found to be good emulsifier (Table 4 and Figure 3). 
Rosenberg (1994) suggested that the natural role of emulsions is to enhance the growth of bacteria on petroleum hydrocarbons. The ability of the extracellular emulsifying agent of Arthrobacter sp, Aeromonas sp, Pseudomonas sp. has been reported (Rosenberg et al., 1979). Emulsification is known to enhance hydrocarbon metabolism (Berg et al., 1990; Hommel, 1993). Stability of emulsion in the presence of salt has been reported as one of the properties of the biosurfactant produced by Bacillus licheniformis strain (Mclnerney et al., 1990). Broderick and Cooney (1982) reported that $96 \%$ of hydrocarbon utilizing bacteria isolated from lakes were able to emulsify kerosene which effectively activity.

Rosenberg et al., (1991) reported that the ability of the extracellular emulsifying agent of Arthrobacter sp, Aeromonas and Bacillus sp. to emulsify crude oil and fractions of crude oil, is, gas oil was a better substrate induced emulsification than kerosene. In fact, emulsions of gas oil were as stable as crude-oil emulsions. Diesel light petroleum has yielded emulsions and the emulsions derived from kerosene and gasoline were unstable. Pentane and hexane also were not emulsified effectively; however quantitative data for these tow paraffins were not obtained because of extensive evaporation during incubation. A higher emulsifying activity has been reported that the biosurfactant produced by Pseudomonas. The emulsions were stable at temperatures ranging from $0^{0} \mathrm{C}$ to $100^{\circ} \mathrm{C}$ (Rosenberg, 1992).

Most microbial surfactants are substrate specific, solubilizing or emulsifying different hydrocarbons at different rates (Ilori and Amund, 2001). An emulsion is formed when one liquid phase is dispersed as microscopic droplets in another liquid continuous phase (Desai and Banat, 1997). Poor emulsification of some of the hydrocarbons might be due to the inability of the biosurfactant to stabilize the microscopic droplets. Emulsifying biosurfactants that are stable in environments with high $\mathrm{pH}$ and salinity would find applications for bioremediation of spills at seas. The biosurfactant may also be useful for bioremediation works in hot and slightly alkaline environments.

\section{Surface tension measurement}

Surface tension is a measurement of the cohesive energy present at an interface. The molecules of a liquid attract each other. The interactions of a molecule in the bulk of a liquid are balanced by an equal attractive force in all directions.

In the present study, strains of Aeromonas A1, A2, A3, A4, A5, A6 lowered the surface tension of water to $30,25,28,22,20,25,20 \mathrm{mN} / \mathrm{m}$ respectively (Table 5). Several strains of anaerobic bacteria produce biosurfactnats (Grula et al., 1983). However, the observed reduction in surface tension (45 to $50 \mathrm{mN} / \mathrm{m}$ ) was not as large as the observed reduction in surface tension by anaerobic organisms (27 to $50 \mathrm{mN} / \mathrm{m}$ ) (Cooper, 1986). Lowering of surface tension is an important property of hydrocarbon degrading strains which helps in utilization of the hydrophobic substrates (Rahman, 1993) reported a surface tension value of $29.5 \mathrm{mN} / \mathrm{m}$ with $1 \%$ inoculum at the stationary phase. The glycerol medium with $10 \%$ inoculum produced the lowest surface tension value of $29.5 \mathrm{mN} / \mathrm{m}$. An effective microbially produced surfactant can lower this value to $<30 \mathrm{dyn} / \mathrm{cm}$ (Lang and Wanger, 1987). The lowest value of surface tension by Bacillus sp. and Aeromonas sp. was reported by (Takeyama and Matsunaga, 2002). In a study by Oberbremer and Muller-Hurtig (1989), a positive correlation was obtained between reduction in surface tension of the fluid phase in a stirred soil bioreactor and the onset of biodegradation of hydrophobic petroleum hydrocarbons. It has also been previously reported that rhamolipid can mediate reduction in surface tension (Banat et al., 2000; Noordman et al ., 2000).

\section{Biosurfactant estimation}

Biosurfactants, amphiphilic compounds of microbial origin, have advantages over their chemical counterparts in biodegradability and effectiveness at extreme temperature, $\mathrm{pH}$ and in having lower toxicity (Banat et al., 2000).

In the present study out of 6 strains of Aeromonas, A1 shows $0.041 \mathrm{~g} / 1$ of biosurfactant production after 24hrs and at $168 \mathrm{hrs} 0.064 \mathrm{~g} / \mathrm{l}$, A2 shows $0.049 \mathrm{~g} / \mathrm{l}$ at $24 \mathrm{hrs}$ and at $168 \mathrm{hrs} 0.067 \mathrm{~g} / \mathrm{l}$, A3 shows $0.043 \mathrm{~g} / \mathrm{l}$ at $24 \mathrm{hrs}$ and at $168 \mathrm{hrs} 0.064 \mathrm{~g} / \mathrm{l}$, A 4 shows $0.038 \mathrm{~g} / \mathrm{l}$ at $24 \mathrm{hrs}$ and at $168 \mathrm{hrs} 0.056 \mathrm{~g} / \mathrm{l}, \mathrm{A} 5$ shows $0.052 \mathrm{~g} / \mathrm{l}$ at $24 \mathrm{hrs}$ and at $168 \mathrm{hrs} 0.067 \mathrm{~g} / \mathrm{l}$, A6 shows $0.034 \mathrm{~g} / \mathrm{l}$ at $24 \mathrm{hrs}$ and at $168 \mathrm{hrs} 0.049 \mathrm{~g} / \mathrm{l}$ respectively among which the maximum biosurfactant production was show by the A1 at 168hours (Table 6 and Figure 4).

Biosurfactants have been reported to be produced on water soluble compounds such as glucose, sucrose, glycerol, or ethanol (Desai and Banat, 1997). Biosrufactant produced from water-soluble substrates have been reported to be inferior to that obtained with water immiscible substrates (Syldatk et al., 1985; Robert et al., 1989). Such biosurfactants may however be cheaper to produce and useful in food and pharmaceutical industries as it will not required extensive purification. Biosurfactants producing microorganisms may play an important role in the accelerated bioremediation of hydrocarbon contaminated sites (Banat et al., 2000; Rosenberg et al., 1999). Most microbial surfactants are substrate specific, solubilizing or emulsifying different hydrocarbons at different rates (Ilori and Amund, 2001). Moreover, use of biosurfactant producing, hydrocarbon degrading, microorganisms for bioaugmentation to enhance hydrocarbon degradation offer the advantage of a 
continuous supply of a non-toxic and biodegradable surfactant at a low cost (Moran et al., 2000; Rahman et al., 2000c). Environmental factors such as $\mathrm{pH}$, salinity and temperature also affects biosurfactants activity.

Our results indicate that Aeromonas sp. were efficient in biosurfactant production and hydrocarbon emulsification. These results suggests that the use of carbon source like diesel for the biosurcatant production, could enhance the biosurfactant production and there by these strains may be applied for bioremediation of hydrocarbon-contaminated sites and enhanced oil recovery.

V. FiguresandTables
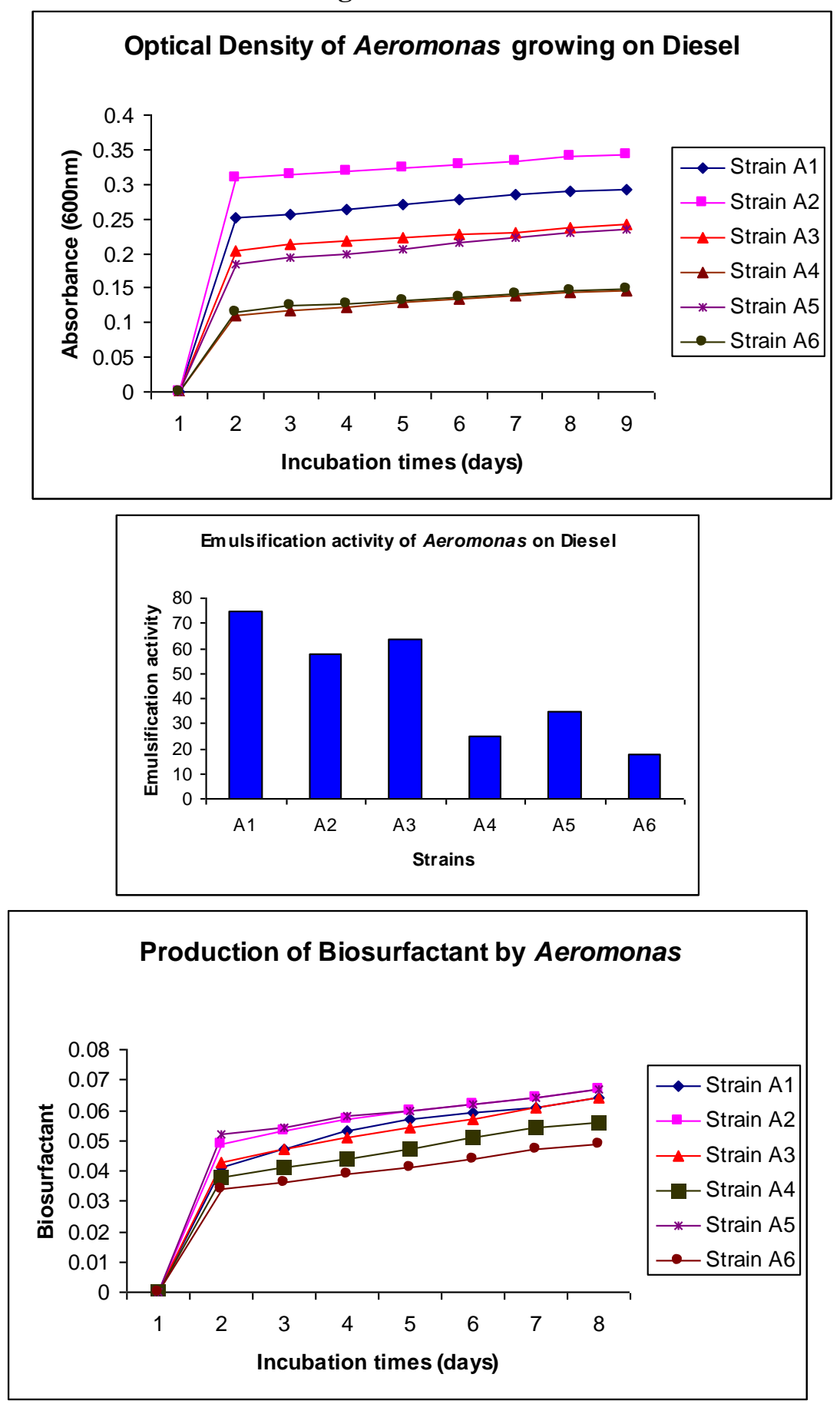
Table 1. Growth range determination of Aeromonas

\begin{tabular}{|c|c|}
\hline STRAINS & TURBIDITY \\
\hline Control & - \\
\hline A1 & ++ \\
\hline A2 & ++ \\
\hline A3 & ++ \\
\hline A 4 & + \\
\hline A5 & ++ \\
\hline A6 & + \\
\hline
\end{tabular}

Table 2. Degradation of diesel by Aeromonas

\begin{tabular}{|c|c|c|c|c|c|c|c|}
\hline $\begin{array}{c}\text { Incubation } \\
\begin{array}{c}\text { Periods } \\
\text { (Days) }\end{array}\end{array}$ & Control & $\mathbf{A 1}$ & $\mathbf{A 2}$ & $\mathbf{A 3}$ & $\mathbf{A 4}$ & $\mathbf{A 5}$ & $\mathbf{A 6}$ \\
\hline 0 & 0.000 & 0.251 & 0.308 & 0.203 & 0.111 & 0.184 & 0.114 \\
\hline 1 & 0.000 & 0.257 & 0.313 & 0.212 & 0.117 & 0.193 & 0.124 \\
\hline 2 & 0.000 & 0.264 & 0.319 & 0.219 & 0.121 & 0.198 & 0.127 \\
\hline 3 & 0.000 & 0.271 & 0.324 & 0.222 & 0.129 & 0.207 & 0.131 \\
\hline 4 & 0.000 & 0.279 & 0.329 & 0.227 & 0.133 & 0.216 & 0.136 \\
\hline 5 & 0.000 & 0.284 & 0.334 & 0.231 & 0.139 & 0.223 & 0.141 \\
\hline 6 & 0.000 & 0.289 & 0.339 & 0.237 & 0.143 & 0.229 & 0.146 \\
\hline 7 & 0.000 & 0.293 & 0.342 & 0.241 & 0.147 & 0.234 & 0.149 \\
\hline
\end{tabular}

Table 3. Biomass Production by Aeromonas

\begin{tabular}{|c|c|c|c|c|c|c|}
\hline Incubation & \multicolumn{2}{|l|}{ Strains/ Biomass } \\
\cline { 2 - 7 } Periods (Days) & $\mathbf{A 1}$ & $\mathbf{A 2}$ & $\mathbf{A 3}$ & $\mathbf{A 4}$ & $\mathbf{A 5}$ & $\mathbf{A 6}$ \\
\hline 2 & 0.05 & 0.03 & 0.05 & 0.02 & 0.03 & 0.02 \\
\hline 4 & 0.07 & 0.05 & 0.06 & 0.04 & 0.04 & 0.03 \\
\hline 6 & 0.09 & 0.06 & 0.08 & 0.05 & 0.06 & 0.04 \\
\hline
\end{tabular}

Table 4. Emulsification activity by Aeromonas

\begin{tabular}{|c|c|c|}
\hline Strains & Hydrocarbon & Percent Emulsified \\
\hline A1 & Diesel & 75 \\
\hline A2 & Diesel & 57.5 \\
\hline A3 & Diesel & 63.75 \\
\hline A4 & Diesel & 25 \\
\hline A5 & Diesel & 35 \\
\hline A6 & Diesel & 18 \\
\hline
\end{tabular}

Table 5. Surface Tension Measurement

\begin{tabular}{|c|c|}
\hline Strains & Surface tension $\mathbf{( m N / m )}$ \\
\hline A1 & 30 \\
\hline A2 & 25 \\
\hline A3 & 28 \\
\hline A4 & 22 \\
\hline A5 & 24 \\
\hline A6 & 21 \\
\hline
\end{tabular}

Table 6. Estimation of biosurfactant by Aeromonas

\begin{tabular}{|c|c|c|c|c|c|c|c|}
\hline \multirow{2}{*}{$\begin{array}{c}\text { Incubation } \\
\begin{array}{c}\text { Periods } \\
\text { (Days) }\end{array}\end{array}$} & Control & A1 & A2 & A3 & A4 & A5 & A6 \\
\cline { 2 - 8 } & 0.000 & 0.041 & 0.049 & 0.043 & 0.038 & 0.052 & 0.034 \\
\hline 1 & 0.000 & 0.047 & 0.053 & 0.047 & 0.041 & 0.054 & 0.036 \\
\hline 2 & 0.000 & 0.053 & 0.057 & 0.051 & 0.044 & 0.058 & 0.039 \\
\hline 3 & 0.000 & 0.057 & 0.060 & 0.054 & 0.047 & 0.060 & 0.041 \\
\hline 4
\end{tabular}




\begin{tabular}{|l|l|l|l|l|l|l|l|}
\hline 5 & 0.000 & 0.059 & 0.062 & 0.057 & 0.051 & 0.062 & 0.044 \\
\hline 6 & 0.000 & 0.061 & 0.064 & 0.061 & 0.054 & 0.064 & 0.047 \\
\hline 7 & 0.000 & 0.064 & 0.067 & 0.064 & 0.056 & 0.067 & 0.049 \\
\hline
\end{tabular}

\section{Conclusion}

The discovery of petroleum brought a lot of relief to the world's energy requirement because of ease of sourcing and conversion. The ease of production, refining and distribution has also brought with it an everincreasing problem of environmental pollution. One of the ways through which petroleum pollutants can be removed is by solubilization and emulsification. Hydrocarbon oxidizing bacteria, fungi and algae are distributed widely in nature. Fertile soil contains significant number of microorganisms that can utilize hydrocarbon as sole source of carbon and energy. As a hydrocarbon mixture, diesel is obtained in the fractional distillation of crude oil between $250^{\circ} \mathrm{C}$ and $350^{\circ} \mathrm{C}$ at atmospheric pressure. It is generally simpler to refine than gasoline. The purpose of present study was to enumerate the diesel degrading Aeromonas and its emulsification activity and production of biosurfactant. The organism used in this study was isolated from oil contaminated soil, the hydrocarbon substrate specificity test showed that diesel is also one of the best substrate for growth and emulsification of biosurfactant by Aeromonas. Among six strains of Aeromonas, first strain shows maximum degradation rate and emulsification of biosurfactant. About $75 \%$ of diesel was degraded by Aeromonas over a period of 7 days. The biosurfactant produced by the diesel degrading Aeromonas sp. represents a new type of biosurfactant with strong emulsifying ability.

\section{FUTURE PROSPECTS}

Identification of Aeromonas strains with proper identity and identification of other microbes which are inhabited in the same natural environment will rive a clear idea about the microbial diversity in the particular automobile service station environment - where petroleum hydrocarbon and detergent levels would be very high. Biosrufactant productivity studies, identification and characterization of biosurfactants by TLC and HPLC will be highly applicable to understand and interaction between microbes and their environment. Emulsification and hydrocarbon degradation studies in the future will give a clear picture about the degradation of petroleum compounds by Aeromonas sp.

\section{Acknowledgements}

"The gracious deeds of the ALMIGHTY are beyond the words of compare". With a warm heart, I thank God for his blessing showered upon me to complete my project work.

I accord my deep sense of gratitude to the founder of K.S.Rangasamy, Educational Institutions, LION.Dr.K.S.RANGASAMY, MJF., Executive Directress of K.S.Rangasamy College of Arts and Science,

I express my gratitude and sincere thanks to Dr. M.GANESAN, Principal, K.S.R College of Arts and Science and Dr. N. KANNAN, Hon. Reader, Department of Biotechnology for their encouragement ,

I owe my true and profound sense of gratitude to thank Dr. G. GURUSUBRAMANIAN, M.Sc., D.Ent., Ph.D., D.T.M.E., D.C.A., PG and Research Department of Microbiology, for his valuable suggestion and successful completion of my project.

I express my whole hearted thanks to Dr. G. VIVEKANANDHAN, M.Sc., M.Phil., Ph.D., Lecturer, PG and Research Department of Microbiology, K.S.R College of Arts and Science for his keen interest, meticulous support, valuable, enthusiastic guidance and brilliant suggestions throughout my project work.

I also avail this opportunity to thank to Dr. A. SANKARANARAYANAN, M.Sc., Ph.D., Head, PG and research department of Microbiology, for his valuable support and assistance that were readily offered to me throughout the course of my study.

I express my whole hearted thank to Dr. K.S.M.Rahman, Biotechnology Research Group, School of biological and environmental sciences, University of Ulster, Coleraine, country Londonderry,Northern Ireland.BT 521SA UK for his valuable support and assistance that were readily offered to me throughout the course of my study.

\section{References}

[1]. Alexander. M. 1995. Biodegradation and bioremediation Chapter 2 New York Academic press.

[2]. Amikam Harounitz., Damid Gutnick and Eugene Roserberg. 1975. Sequential growth of bacteria on crude oil. Applied microbiology, 30: $10-19$.

[3]. Apalijalahti. JHA. and Salkinoja Salonen M.S. 1984. Absorption pentachtorophenol (PCP) by bark chips and its role microbial PCP degradation. Microb. E.coli.10: 359 - 367.

[4]. Atlas. R. M. and R. Bartha. 1972. Degradation and mineralization of petroleum by two bacteria isolated from coastal waters. Biotechnol. Bioeng. 14:297-308.

[5]. Atlas. R.M. 1981. Fate of oil from two major oil spills. Environ. It 5: 33 - 38.,Microbial degradation of petroleum hydrocarbons, an environmental perspective. Microbial Rev. 45: 180 - 209. 
[6]. Atlas. R.M. 1990. Microbial hydrocarbon degradation-bioremediation of oil spills. J. Chem. Tech. Biotechnol. 52:149-156.

[7]. Atlas. R.M. 1995. Bioremediation of petroleum pollutants. Int. Biodeterior. Biodegrad., 21, 317-327.

[8]. Atlas. R.M. and Bartha. R. 1992. Hydrocarbon biodegradation and oilspill bioremediation Adv. Microb. Eco. 12.287.338.

[9]. Atlas. R.M. and R. Bartha. 1972. Biodegradation of petroleum in sea water at low termpatures. Can. J.Mcirobiol. 18:185-195.

[10]. Banat. I. M., R.S. Makkar and S.S. Cameotra. 2000. Potential commercial application of microbial surfactants. Appl. Microbiol. Biotechnol. 53: 495-508.

[11]. Banat. I.M. 1995. Biosurfactants production and use in microbial enhanced oil recovery and pollution remediation. A review. Biores. Technol. 51, 1-12.

[12]. Banerjee. S., Duttagupta, S. and Chakrabarty, A.m., 1983. Arch. Microbiol. 135, $110-114$

[13]. Barathi. S., and Vasudevan. N. 2001. Utilization of petroleum hydrocarbons by Pseudomonas fluorescens isolated from a petroleum - contaminated soil. Env. Int., 26:413-416.

[14]. Bartha. R. 1986. Biotechnology of petroleum pollutant Biodegradation microbial Ecol. 12: 155 - 172.

[15]. Bauchop. T., and Elsden. S.R. 1969. The growth of microorganisms in relation to their energy. J. Gen. Microbial. 23,457-469.

[16]. Berg. G., Seech, A.G. Lee, H. and Trevors, j. T., 1990. J. Environ. Sci. Health. A 25, $753-764$.

[17]. Bergey. D.H. 1939. Manual of Determinative Bacteriology. $5^{\text {th }}$ Ed., Baltimore, Williams and Wilkins Company, 1032pp.

[18]. Blumer. M. 1971. Scientific aspects of the oil spill problem. Environ. Aff. 1:57-73.

[19]. Bossert. I. and Bartha. R. 1984. The fate of petroleum and soil ecosystems. In: Petroleum Microbiology, ed. Atlas, R.M. New York: Macmillan Publishing Co. 434-476.

[20]. Broderick. L.S. and Cooney. J.J. 1982. Emulsification of hydrocarbons by bacteria from fresh water ecosystems. Dev.Ind.microbiol. 23: 425 - 434.

[21]. Candler. JE., Rushing. JH. and Leuteman. AJJ. 1993. Synthetic-based mud systems. SPE Paper 25993, In: SPE/EPA. Exploration and Production Environmental Conference, San Antonio, Texas, USA, 7-10 March 485-499.

[22]. Chakrabarthy. A.M. 1976. Plasmids in Pseudomonas. Annu.Rev.Genet. 10: 7 - 30.

[23]. Chhatre. S., Purohit. H.J., Shanker. R and Khanna. P. 1996. Bacterial consortia for crude oil spill remediation. Water Sci. Technol. 34, 187-193.

[24]. Conomoe. T.J. 1975. Movement of applied oil an predicted by estuarism nontidal drift. Limnol. Oceanogr. 20: 159-173.

[25]. Del'Arco, J.P and De Franca. F.P. 1999. Biodegradation of crude oil in sendy sediment. Int. Biodeter. Biodegrad. 44, 87-92.

[26]. Desai, A. J., Patel, K.M. and Desai, J.D. 1987,88. Curr. Sci. 57, 500-501, Microbial surfactants evaluation, tyupes and future applications placations. J.Sci.Ind.Res. 46: 440 - 449.

[27]. Desai. J.D. and Banat. I.M. 1997. Microbial production of biosurfacants and their commercial potential. Microbiol. Mol. Bio. Rev. 61: $47-64$.

[28]. Dibbel. J.T. and R. Bartha. 1976. Leaching aspects of oil sludge biodegradation in soil. Sci., $127: 365-370$.

[29]. Donaldson. E.C., G.V. Chilingarian and T.F. Yen. 1989. Introduction. In Microbial enhanced oil recovery. Elsevier, New York, N.Y. 1-15.

[30]. Duvnjak. Z., Cooper. D.G., and Kosaric. N. 1983. Effect of nitrogen source on surfactant production by Arthrobacter paraffines ATCC 19558. In: Zajic, J.E., Cooper, D.G., Jack, T.R., Kosaric, N. (Eds.), Microbial Enhanced Oil recovery. Pennwell Books, Tulsa, Oklahoma, USA, 66-72.

[31]. Ellis. W.D., Payne, J.R. and Monabb G.D., 1985. Treatment of Contaminatn soils with Aqueous Surfactants, United States environmental Protection Agency, Office of Research and Development.

[32]. Enrlich. G.G., Schroeder. R.A. and Martin. P., 1985. Microbial Populations in a jet Fuel contaminated Aquifer at Tustin, Californa, US geological Survey Report, 85.

[33]. Fehler. S.W.G and R.J. Light. 1970. Biosynthesis of hydrocarbons in Anabaena variabilis. Incorporation of (methyl-C) and (methylH) - methionine into 7-and 8-methyl-heptadecanes. Biochemistry. 9:418-422.

[34]. Ferrari. M.D., Neirotti. E., Albornoz. C., Mostazo. and M.R., Cozzo. M. 1996. Biotreatment of hydrocarbons from petroleum tank bottom sludges in soil slurries. J. Biotechnol. Lett., 18:1241-1246.

[35]. Fingas. M, Environment Canada, Personal communication, 1990.

[36]. Floodgate. G. 1984. The fate of petroleum in marine ecosystems. In: Petroleum Microbiology, ed. Atlas, R.M. New York: Macmillan Publishing Co. 335-398.

[37]. Fought. J. M., Gutnick. D.L and Westlake. D.W.S., 1989. Appl. Environ. Microbiol, 55, 36 - 42.

[38]. Frankenberger. Jr. W.T. 1992. The need for a laboratory feasibility study in bioremediation of petroleum hydrocarbons. In: Calabrese, E.J.; Kostecki, P.T. (eds.) Hydrocarbon contaminated soils and groundwater. Lewis Pub., Boca Raton, FL, 237-293.

[39]. Gary Canny (Email: cannyg@ @students. Itsligo i.e., Dr. Michael Broaders (Email. broaders, Michael@itsligo.ie., 1997.

[40]. Gatellier. C.R. 1971. Less features limitant la biodegradation deshydrocarbures dans puration des eaux. Chim.Ind (Paris) 104: $2233-2289$

[41]. Gillam. A.H., and Gibson. M.J. 1986. Chemical monitoring in the North sea. Chemistry in Britain. Oct. 911-913.

[42]. Grula. E.A., Russell. H.H., Bryant. D., Kenaga. M and Hart. M., in Proceedings of the 1983. International conference on microbial department of Energy, Bartlesville, 43.

[43]. Gunkel. W. 1968. Bacteriological investigations of oil polluted sediments from the Cornish coasts following the "Torrey canyon" disaster. In J.D Carthy and D.R Arthu (Ed). The biological effects of oil pollution on littoral communities (Supplement to field Stud. 2) E.W.classey, Ltd.,

[44]. Hardwood. J. L. and N.J. Russel. 1984. Lipids in plants and microbes, george Allen and Unwin Ltd. London, U.K. 110-111.

[45]. Hommel. R.F. and C. Ratledge. 1993. Biosynthetic mechanisms of low molecular weight surfactants and their precursor molecules. $3-63$.

[46]. Hommel. R.K. 1990. Formation and physiological role of biosurfactants produced by hydrocarbon-utilizing microorganisms. Biodegradation 1:107-110.

[47]. Hunt. J. M., R.J. miller and J.K. Whelan. 1980. Formation of C-C hydrocarbons from bacterial degradation of naturally occurring terpenoids. Nature (London), 288:577-578.

[48]. Ilori. M.O., and Amund. O.O. 2001. Production of a peptidoglycolipid bioemulsifier by Pseudomonas aeruginosa grown on hydrocarbon. Z. Naturforsch. 56C, 547-552.

[49]. Ilori. M.O., C.J. Amobi and A.C. Odacha. 2005. Factors affecting biosurfactant production by oil degrading Aeromonas spp. isolated from a tropical environment. Chemosphere 61: $985-992$.

[50]. Iqbal. S., Khalid. Z.M. and Malik K.A. 1995. Enhanced biodegradataion and emulsification of crude oil and hyper production of biosurfactants by a gamma ray induced mutant of Pseudomonas aeruginosa. Let Appl. Micro, 21: 176 - 179. 
[51]. J.D. Walker., R.R. Colwell and L. Petrakis. 1975. Evaluation of petroleum degrading potential of bacteria from water and sediments. Applied microbiology 30 (6), 1036 - 1039

[52]. Jain. D.K., Lee. H and Trevors. J.T. 1992. Effect of addition of P. aeruginosa UG2 inocula or biosurfactants on biodegradation of selected hydrocarbons in soil. J. Ind. Microbiol. 10:87-93.

[53]. Jobson. A., F. D. Cook and W.S. Westlake. 1972. Microbial utilization of crude oil. Appl. Microbial. 24:1082-1088.

[54]. Jobson. A., M. McLaughlin, F.D. Cook and D.W.S. Westlake. 1973. Effect of Amendments on the microbial utilization of oil applied to soil. Applied. Microbiology. 166-171.

[55]. John Wiley and Sons. 1982. Encyclopedia of chemical Technology $3^{\text {rd }}$ ed. 17:119-130.

[56]. Juttner. F. 1976. $\beta$-Cyclocitral and alkanes in microcystis (Cyanophyceae). Zeitschrift fur Naturforschung. 31c, 491-495-503.

[57]. Kaja Sheik Mujibur Rahman, Thanhira Rahman, Perumal Lakshmanaperumalsamy and Ibrahim M. Bana. 2003. Occurrence of crude oil degrading bacteria in gasoline and diesel station soils. J.Basic.Microbial. 42: 286 - 293.

[58]. Karanth, N.G.K., P.G. Deo and N.K. Veenanadig. 1999. Microbial production of biosurfactants and their importance.

[59]. Kaserer. H. 1906 Uber die Oxydation des Waserstoffes and des Mothans durch Mikroorganismen. Zentr. Bakt. Parasitenk., Abt II, 15: 573-576.

[60]. Kastner. M., Breuer-Jammali, M and Mahro. B. 1994. Enumeration and characterization of the soil microflora from hydrocarbon-contaminated soil sites able to mineralize polycyclic aromatic hydrocarbons (PAH). Appl. Microbiol. Biotechnol. 41, $267-273$

[61]. Kastner. M., Breuer-Jammali and M., Mahro, B. 1994. Enumeration and characterization of the soil microflora from hydrocarbon-contaminated soil sites able to mineralize polycyclic aromatic hydrocarbons (PAH). Appl. Microbiol. Biotechnol. 41, $267-273$.

[62]. Klevans. H.B. 1954. Solubilization of polycylic hydrocarbons J. Phys. Colloid Chem., 54: 283-298.

[63]. Kolattukudy. P.E., J.S. Buckner and L. Brown. 1972. Direct evidence for a decarboxylation mechanism in the biosynthesis of alkanes in B. oleracea. Biochem. Biophys. Res. Commun. 47:1306-1313.

[64]. Kornelli. T.V., Koaroua, T.L. and Yu. V. Denisov. 1983. Microbiology 52, 767-770.

[65]. Kosaric. N., Cairn. W.L.S., Gray and N.C.C. (eds) 1987. Biosurfactants and Biotechnology, surfactant Science Series, vol. 25, Marcel Dekker.

[66]. Kretschmer. A., Bock. H and Wagmer. F. 1964. Characterisation of biosynthetic intermediates of trehalose dicorynemycolates from Rhodococcus erythropolis on n-alkanes, Appl. Environ. Microbiol, 44 (1982).

[67]. Kroos. H, domestic and International, Atlanta, 1989.

[68]. Lal. B and Khanna. S. 1996. Degradation of crude oil by Acinetobacter calcoaceticus and Alcaligenes odorans. J. Appl. Bacteriol. 81, 355-362.

[69]. Lang S., and F. wagner. 1987. Structure and properties of biosurfactants, p.,21 - 47. In N.Kosaric, W.L Cairns, and N.C.C. Gray (ed.), Biosurgfactants and biotechnology. Marce Deker, Inc., new York, N.Y.

[70]. Lang. S and Wanger. F. 1987. Structure and properties of biosurfactants. Surfactant Science Ser 25: 21-45.

[71]. Leahy. J.G. and R.R. Colwell. 1990. Microbial degradation of hydrocarbons in the environment. Microbiol. Rev. 54:305-315.

[72]. Margesin. R. and F. Schinner. 1997. Efficiency of Indigenous and Inoculated cold-adapted soil Micro-organisms for Biodegradation of Diesel Oil in Alphine soils. Appl. Environ. Microbial 67(7): 2660-2664.

[73]. McClay. K., B.G. Fox and R.J. Steffan. 2000. Toluene monooxygenasecatalyzed epoxidation of alkenes. Appl. Environ. Microbiol. 66: 1877-1882.

[74]. McLnerney. M.J., Javaheri. M and Nagle. D.P. 1990. Properties of the biosurfactant produced by Bacillus licheniformis strain JF-2. J. Ind. Microbiol. 5, 95-102.

[75]. Meredith. W., Kelland. S.J and Jones. D.M. 2000. Influence of biodegradation on crude oil acidity and carboxylic acid composition. Org. Geochem. 31, 1059-1073.

[76]. Midwest Biofuels Inc. 1993. Soy Diesel in biodegradability and toxicity technical information. In, Biodiesel information kit received from National Soy Diesel Development Board, Overland Park, K.S.

[77]. Miget. R.J., C.H. Oppenheimer, H.I. Kater and P.A. LaRock. 1969. Microbila degradation of normal paraffin hydrocarbons in crude oil. In proceedings joint conference on prevention na dcontrol of oil spills. API/FWPCA Conference, U.S. Department of Interior, Washington, D.C. 327-331.

[78]. Mikkelson. J.D., and P. Von Wettstein-Knowles. 1978. Biosynthesis of $\beta$-diketones and hydrocarbons in barley spike epicuticular wax. Arch. Biochem. Biophys. 188:172-181.

[79]. Moran. A.C., Olivera. N., Commendatore. M., Esteves. J.L and Sineriz. F. 2000. Enhancement of hydrocarbon waste biodegradation by addition of a biosurfactant from Bacillus subtilis 09. Biodegradation 11, 65-71.

[80]. Morgan. P and Watkinson. R.J, 1989. CRC Crit. Rev. Biotechnol., 1989, 8, 305 - 333.

[81]. Oberbremer. A., Muller Hurtig. R and Wagner. F., 1990. Appl. Microbial. Biotechnol. 32, 485 - 489.

[82]. Obire. O. and I.V. Okudo. 1997. Effects of Crude oil on a Freshwater Stream in Nigeria. Discov. Innov. 9:25-32.

[83]. Obire. O. and Nwaubeta. O. 2001. Biodegradation of Rejined petroleum hydrocarbons in soil. Journaly of applied sciences, and environmental management. 5(1) $43-46$.

[84]. Okerentugba. P.O and O.U. Ezeronye. 2003. Petroleum degrading potentials of single and mixed microbial cultures isolated from rivers and refinery effluent in Nigeria. African Journal of Biotechnology 2(9), 288-292.

[85]. Olivera. N.L., Esteves. J.L., and Commendatore. M.G. 1997. Alkane biodegradation by a microbial community from contaminated sediments in Patagonia, Argentina. Int. Biodeter. Biodegrad. 40, 75-79.

[86]. Osenga. M. 1993. What exactly is biodiesel? Diesel progress engines and drives. In, National Soy Diesel Development Board Alternative Fuels Special Report.

[87]. Payne. J.R. and McNabb. D.G.Jr. 1984. Weathering of petroleum in the marine environment, MTS Journal. $18: 24-42$.

[88]. Portier. R., Bianchini., Fujusaki. K., Henery. C. and Macmillin. 1998. Comparison of effective toxicant biotransformation by autochthonous microorganisms and commercially available cultures in the insitu reclamation of abandoned industrial sites, Schriftner, ver Wasser baden Iuftthy g, Berlin dehlem. $80-273$.

[89]. Prince. R.C. R. Varadaraj, R.J. Fiocco and R. R. Lessard. 1999. Bioremediation as an oil response tool. Environ. Technol. 20:891-896.

[90]. Rahman. K.S.M, I.M. Banat., J. Thahira, Tha. Thayumanavan and P. Lakshmanaparumalsamy. 2002. Bioremediation of garoline contaminated soil by a bacterial consortium amended with poultry litter, coil pith and rhamndipid Biosurfactant Bioresource technology. 81: 25-32.

[91]. Rahman. K.S.M., Thahira-Rahman. J., Lakshmanaperumalsamy. P. and Banat. I.M. 2002c. Towards efficient crude oil degradation by mixed bacterial consortium. Bioresour. Technol. 85, 257-261. 
[92]. Ramana, K.V. and Karanth, N.G.K., 1989. J. Chem. Technol. Biotechnol., 45, $249-257$.

[93]. Raymond. R.L., Hudson. J.O and Jamison. V.W. 1976. Oil degradation in soil J.Appl. Environ. Mcirobial. $31: 522$ - 35.

[94]. Rosenberg. E. 1991. Hydrocarbon Oxidizing bacteria. In the prokaryotes, ed. A.Ballows. $441-59$.

[95]. Rosenberg. E., and Ron. E.Z. 1999. High molecular mass microbial surfactants, J.Appl., Micrbiol, Biotechnol, 52 : 154 - 162.

[96]. Rosenberg. E., Zukerberg. A., Rubinovitz. C and Gutnick. D.L. 1979. Emulsifier of Arthrobacter RAG-1, Isolation and emulsifying properties. Appl. Environ. Microbial. 37, 402-408.

[97]. Schmidt. S.K. and Alexander. M. 1985. Effects of dissolved organic carbon and second substrates on biodegradation of organic compounds at low concentration J.Appl. Environ, Microbiol., 49: 822 - 827.

[98]. Seklemova. E., Pavlova. A. and Kovacheva. K. 2001. Biostimulation-based bioremediation of diesel fuel: Field demonstration. Biodegrad. 12:311-316.

[99]. Shimp. R.J. and Pfaender. F.K. 1985. Influence of easily degradable naturally occurring carbon substrates on biodegradation of monosubstituted phenol by aquatic bacteria. J.appl. Environ. Microbial. 49: $394-401$.

[100]. Singer. M.E. and W.R. Finnerty. 1984. Microbial metabolism of straight-chain and branched alkanes. In, R.M. Atlas (ed.), Petroleum Microbiology, Macmillan Publishing, New York. 1-60.

[101]. Sohngen. N.L. 1906. Uber Bakterien, welche Methan als Kohlenstoffinahrug Energiquelle gebrauchen. Zentr. Bakt. Parasitenk., Abt. II, 15; 513-517.

[102]. Steffan. R. J., K. Mccloy., S. Vain berg., C.W. Condee and D. Zhang, 1997. Biodegradation of the Gasoline Oxygenates Methyle tert-Butyl Ether, Ethyl tert-Butyl Ether and tert-Amyl Methyl Ether by Propane-Oxidizign Bacteria. Appl. Environ. Microbiol. 63(11): 4216-4222.

[103]. Stella. O., Ajisebutu. 1988. Effectsof sodium chloride on biodegradation of crude oils by two species of Aeromonas. Applied. Microbiology and Biotechnology. 28 (2), 203-208.

[104]. Stone. R.W., White. A.G.C. And Fenske. M.R. 1940. Microorganisms attacking petroleum and petroleum factions. I.bact., 39: $91-92$.

[105]. Sugiura. K., Ishihara. M., Shimauchi. T and Harayama. S. 1997. Physicochemical properties and biodegradability of crude oil. Environ. Sci. Technol. 31, 45-51.

[106]. Syldatk. C. and F. Wagner. 1987. Production of biosurfactants. In n.Kosaric, W.L.Cairns, N.C.C gray, (ed) Biourfactants and biotechnology Marcel Dekker, Newyork. $89-12$.

[107]. Takeyama. H., Wada. M. and Masunaga. T. 2002. Screening of soil bacteria for production of biocleaner. Applied Biochemistry and Biotechnology, 98 (1-3), 319-326(8).

[108]. Traxler. R.W. 1973. Bacterial degradation of petroleum materials in low temperature marine environments. $163-170$.

[109]. Van Dyke. M.L., H. Lee and J.T. Trevers. 1991. application of microbial surfactants. Adv., 9. $241-252$.

[110]. Vasudevan. N. and Rajaram. P. 2001. Bioremediation of oil sludge-contaminated soil. Environ. Int. 26, 409-411.

[111]. Venkateswaran. K. and Harayama. S. 1995. Sequential enrichment of microbial populations exhibiting enhanced biodegradation of crude oil. Can. J. Microbiol., 41, 767-775.

[112]. Vivekanandhan. G., N. Vasudevan and P. Lakshmanaperumalsamy. 1999. Degradation of crude oil by a bacterial consortium. 18(3), 245-249.

[113]. Voroshilova. A. A. and E.V. Disnova. 1950. Bacterial oxidation of oil and its migration in natural waters Mikrobiologiya 19:203210 .

[114]. Walker, J.D and Colwell, R.R. 1974. Microbial degradation of model petroleum at low temperatures. 1, 63-95.

[115]. Walker. J.D., R.R. Colwell. 1976a. Measuring potential activity of hydrocarbon degrading bacteria. Appl. Environ. Microbiol. 31:189-+197.

[116]. Walker. J.D., and R. Colwell. 1976b. Enumeration of petroleum-degrading microorganisms. Appl. Environ. Microbiol. 31:198207.

[117]. Ward. D.M., R.M. Atlas, P.D. Boehm and J.A. Calder, 1980. "Microbial Biodegradation and the Chemical Evolution of Amoco codiz Oil Pollutants" Ambio, vol. IX, No. 6, 279.

[118]. Wasko. M.P and Bratt. R.P. 1990. Properties of a biosurfactant produced by the fuel contaminant Ochorbactrum anthrrpii. Inter. Biodeter., 27, $265-73$.

[119]. Wilkinson, S.G and Cordell. 1985 Studies on lipopolysaccharides from Pseudomonas aeruginosa. Eur. J.Biochem. 52 : 331 - 343.

[120]. Winters. K., P.L. Parker and C. Van Baalen. 1969. Hydrocarbons of the blue-green algae: Geochemical significance. Science. $163: 467-468$

[121]. Wong. J.H.C., Lim. C.H. and Nolen. G.L. 1997. Design of Remediation Systems; Lewis Publishers Ed.; United States of America.

[122]. Yeung. P.Y., Johnson. R.L., Xu. J.G. 1997. Biodegradation of petroleum hydrocarbons in soil as affected by heating and forced aeration. J. Environ. Qual. 26, 1511-1516.

[123]. Zajie. J.E., Guignard. H. and Gerson. D.F, 1977. Properties of biodegradation of bioemulsifier from corynebacterium hydroclastus, Biotechnol Bioeng, 191-303.

[124]. Zhang. Y., and Miller. R.M. 1992. Enhanced octadecane dispersion and biodegradation by a Pseudomonas rhamnolipid surfactant (biosurfactant). Appl. Environ. Microbial. 58, 3276-3282.

[125]. ZoBell. C. E. and J.F. Prokop. 1946. Microbial oxidation of mineral oils in Barataria Bay bottom deposits. Z. Allg. Mikrobiol. 6:143-162.

[126]. ZoBell. C.E. 1969. Microbial modification of crude oil in the sea, p.371-326. Proc. API/FWPCA Conference on Prevention and control of Oil Spills. Atherican Petroleum Institute publ. No.4040. 